\title{
AN EXPERIMENTAL STUDY FOR QUALITY ASSURANCE OF FREE-FORM CONCRETE PANELS PRODUCED BY CNC MACHINE
}

\author{
Jeeyoung LIM, Do Yeong KIM, Sunkuk KIM* \\ Department of Architectural Engineering, Kyunghee University, 1732 Deogyeong-daero, \\ 17104, Yongin-si, Republic of Korea
}

Received 17 October 2017; accepted 27 February 2018

\begin{abstract}
Various studies have been conducted to construct free-form buildings, but it still takes a lot of labor, cost, and time to assure the accuracy of designed shapes. In particular, molds for the production of free-form concrete panels (FCPs) are putting enormous burdens on productivity and cost. To produce FCPs economically, a computerized numeric control (CNC) machine that produces phase change material (PCM) molds for persistent use was developed in this study. The technology using CNC machine can produce precisely free-form molds and panels in a short time compared to the manual method. However, in order to commercialize this technology, it is necessary to verify the shape error of the FCPs. Therefore, the purpose of this paper is an experimental study for securing FCP quality produced by a CNC machine. The results of this study will be used to mass-produce uniform quality of FCPs without depending on the skill and workmanship of the labor.
\end{abstract}

Keywords: experimental study, free-form concrete panel, production technology, quality assurance, CNC machine, flexible formwork.

\section{Introduction}

Although many technologies have been applied to the construction of free-form buildings with enormous capital input (Kim 2009), there are still very few technologies to produce high-quality free-form members with economic-feasibility (Payne 2003; Plaza 2006). In the case of the Sydney Opera House, the initial estimated total construction cost was 7 million USD, but increased 15 times to 120 million USD (Payne 2003), the total construction cost of the Bilbao Guggenheim Museum was 127 million USD, 14 times more than the initial budget (Plaza 2006). Dongdaemun Design Plaza \& Park (DDP), a monumental free-form building in Korea, took twice the initial budget due to frequent change order and time delay (Kim 2014).

The reason for the rise of the construction cost is the large amount of manpower and time spent in the design, production, and installation stages to secure the quality of the free-form building facade. In particular, the cost of producing and installing free-form panels is more than twice that of normal panels. In the case of free-form con- crete panels (FCPs), the production mold or form is not reusable or recyclable, resulting in a huge burden on productivity and cost (Lee 2015; Kim et al. 2015).

To solve this problem, a computerized numeric control (CNC) machine was developed to produce molds for freeform concrete panels of precise shape in a short time. The $\mathrm{CNC}$ machine receives the shapes of the designed freeform concrete members as meshed data and implements the shapes of FCPs into phase change material (PCM) molds by a series of mechanical operations. In this process, there is an error between the designed shape and the manufactured shapes. The shape errors are caused by the errors caused by the rubber plate used to make the shape and by the accumulated mechanical errors due to the operation of the $\mathrm{CNC}$ machine parts. Therefore, in order to commercialize the developed technology, it is necessary to verify the shape errors of the FCPs. Therefore, the purpose of this paper is an experimental study for securing FCP

*Corresponding author. E-mail: kimskuk@khu.ac.kr 
quality produced by a CNC machine. This study is carried out as follows:

1. Reviewing the problems of production technology of free-form members through the literature survey, and introducing the process of FCP production by the CNC machine developed in this study;

2. Designing the FCP based on the curvature and size of an external cladding of the building after selecting a free-form building case;

3. Establishing the experiment plan by using CNC machine in order to secure the quality of FCP;

4. Measuring the coordinate value of meshed design data to be transferred to the CNC machine;

5. Comparing the difference between the coordinate values of the designed FCP and the shape plate implemented by the CNC machine;

6. Analyzing the results of experimental research to identify problems and draw out improvements.

\section{Preliminary study}

\subsection{Review of production technology of free-form members}

3D design technology using BIM and CNC machining technology were continuously studied by investing a huge amount of research fund in the area of free-form concrete panels' production technology (Ryu, Kim 2012; Bae et al. 2009; Lee 2008). However, in most construction projects, it is difficult to reuse the molds or forms used for the production of FCPs. For this reason, constructing a free-form building still puts a huge burden on cost, time and productivity.

In a study on the production technology of FCPs, Latorre (2010) used a pneumatic system to make a shape of a free-form dome, but it was difficult to implement various shapes. Verhaegh (2010) implemented FCPs using a fabric form, but additional research on how to reinforce and reuse flexible fabrics is needed. For automation of free-form panel concreting, The CRAFT (Center for Rapid Automated Fabrication Technologies) at the University of Southern California (USA) has studied numeric controlled machine, production process, new material and design using computer, and studied the manufacture and utilization of large machines for automation in building construction (CRAFT 2014). However, further studies are required for the production of large size free-form panels.

The IMCRC (Innovative Manufacturing and Construction Research Center) of Loughborough University in England has studied 3D printing method to produce FCPs (IMCRC 2014). However, due to the production by the plotting method, production of a panel takes a long time and large quantity production is impossible in terms of cost. And the issues of securing the bonding strength between the plotted layers and trowelling to make the smooth shape should be solved (Kim 2014).

In addition, EPS (Expandable Polystyrene) processed by CNC machine (Mandl et al. 2008; Lindsey, Gehry 2001), wood (Ito 2006) and fabric (Schipper, Janssen 2011) were used as forms or molds in their researches or projects on free-form building technology. However, these studies need more practical studies considering economic efficiency due to the problem of being used only once. Oesterle et al. (2012) presented the concept of a free-form mold that can be recycled using wax as shown in Figure 1(a). Although the concept of the research level was presented, detailed techniques including the details of the equipment for the production of the free-form concrete panel and the production process considering the characteristics of the wax were not provided.

As shown in Figure 1(b), Savvides (2012) developed a 3FST (free form formwork system technology) to create free-form shapes that can be recycled using regularly spaced rods. This technique requires additional treatment because the surface of the cured concrete is rough as shown in the Figure 1(b). Since the geometric error of free-form shape was not verified, it stayed at the level of suggestion.

The machines studied in 4TU (2017), Schipper and Eigenraam (2016) and Adapa (2017) as shown in Figure 1(c) and (d) implements a free-form shape with a steel plate. However, when the steel plate is deformed at an irregular shape in a flat state, expansion due to tension does not occur like a rubber plate in which four edges are constrained. Therefore, Figure 1(e), the projected size does not maintain the size in the flat state after the irregular shape is implemented. That is, the size of the initial flat state is reduced according to the curvature. Since all free-form panels have different curvatures, the size of the flat plate should be accurately calculated considering that the size is reduced as shown in Figure 1(f). However, it is not easy to calculate the initial size of the flat state even in one panel considering the free-form shape to be implemented, while maintaining smooth size change.

If a free-form panel is produced using the method proposed by 4TU (2017), Schipper and Eigenraam (2016) and Adapa (2017), the original flat size must be changed. Thus, it is possible to make one panel experimentally by these methods, but it is very difficult to precisely produce external or internal finishes with many panels in precise layout. In addition, no verification test for the shape error after panel fabrication has been performed in their research.

As mentioned above, many studies have been carried out on the production of free-form concrete members, but it still takes a lot of time and money to produce the members that match the designed free-form shape. To solve these problems, a CNC machine that operates the rods up and down was developed as shown in Figure 2. The CNC machine developed in this study quickly and accurately implements 3D free-form panel information. That is, the free-form shape shown in the drawing is implemented mechanically.

CNC machine consists of multiple numerical control rods (NCRs, (1) that move up and down and they are arranged in $7 \times 7$ grid (Lim et al. 2016b). Before starting the motor (2), the initial NCRs position can be set. And the information on initial position is delivered to a computer through the data acquisition (DAQ) board (6). When the 


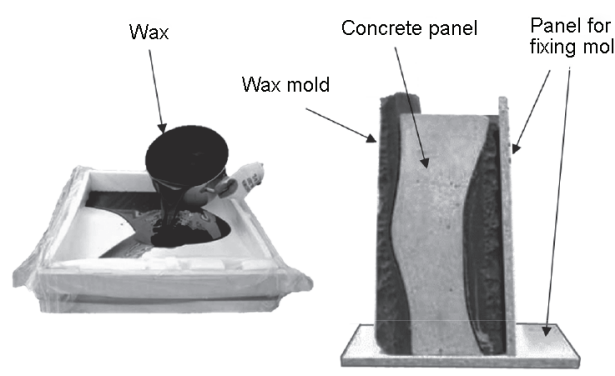

(a) Form manufacturing using wax and concrete panel (Oesterle et al. 2012)

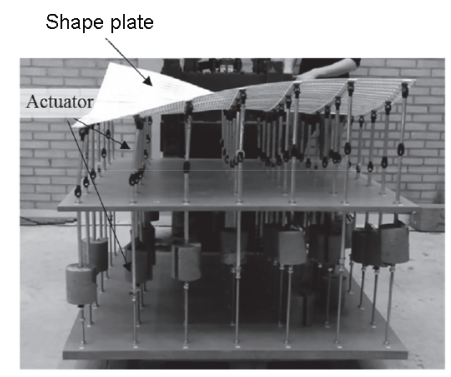

(c) Prototype built in the project Kine-Mould (4TU 2017; Schipper, Eigenraam 2016)

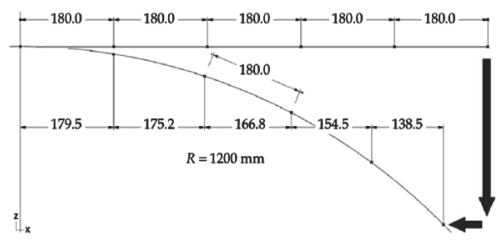

(e) Principle of Kine-Mould (Schipper, Eigenraam 2016)

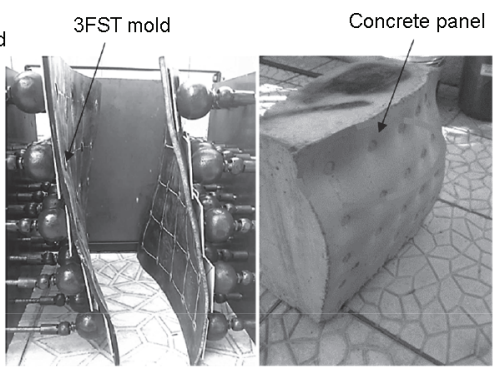

(b) Form manufacturing using 3FST and concerete panel (Savvides 2012)

Shape plate

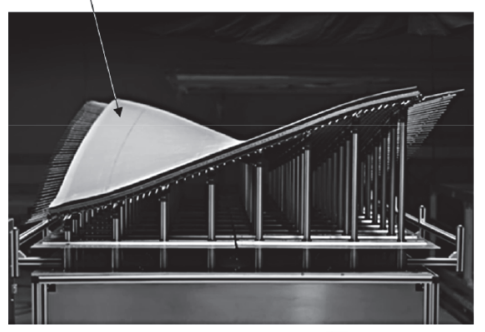

(d) Mold controlled by computer (Adapa 2017)

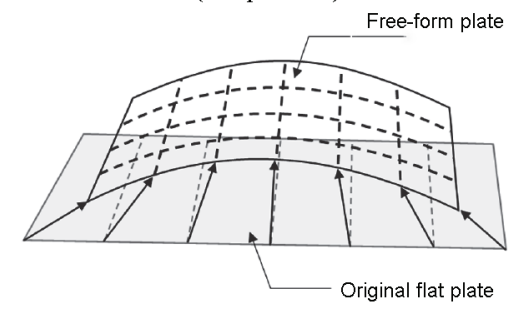

(f) Size variation of flat plate

Figure 1. Experimental cases for FCP production

curved surface information is inserted on the computer, it is sent to the motor driver (3) through the motor control board (5).

Here, this bar-shaped motor driver moves to each motor (seven motors) along the moving rail (4) and it can individually control the NCR height of the corresponding row. In other words, the motor driver moves from Y1 row to $\mathrm{Y} 2$ row and from $\mathrm{Y} 2$ row to $\mathrm{Y} 3$ row. This is repeated until it moves from $\mathrm{Y} 6$ row to $\mathrm{Y} 7$ row. Then, the motor driver controls the NCR height at each row. The operation ends when one FCP shape is completed.

The driving time of the CNC machine is calculated by the following Eqn (1) considering the screw lead, total transmission distance, number of screws, motor speed and

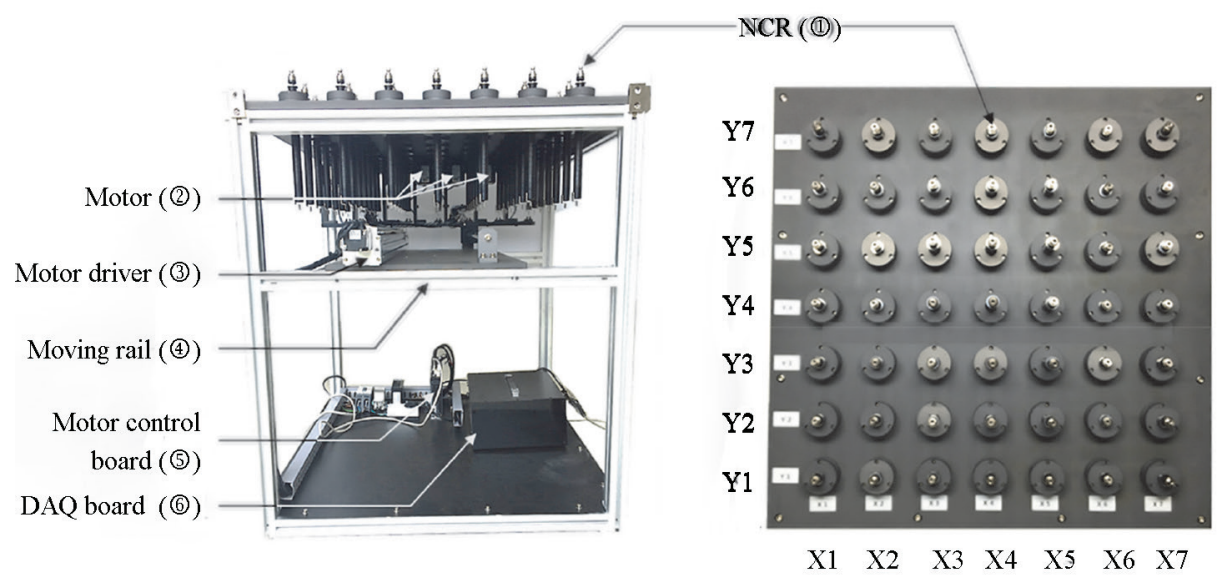

(a) General perspective view

(b) Plane view

Figure 2. CNC machine 
gear ratio. The total possible driving time is 4.8 seconds, which is designed to be 14.4 seconds by applying a safety factor of 3 times:

$$
T=\frac{x_{3} \times \frac{x_{2}}{x_{1}}}{x_{4} \times x_{5}}=\frac{7 \times \frac{100}{3}}{3000 \times 1}=0.08 \mathrm{~min}=4.8 s,
$$

here $x_{1}$ : Screw lead $=3 \mathrm{~mm} ; x_{2}$ : Transmission distance $=100 \mathrm{~mm} ; x_{3}$ : Number of screws $=7 \mathrm{EA} ; x_{4}$ : Motor speed $=3,000 \mathrm{RPM} ; x_{5}:$ Gear ratio $=1: 1$.

The concept of producing FCPs using CNC machine is shown in Figure 3. The description of each step is as follows.

1. As shown in Figure 3(a), the pattern data produced from parametric modeling are defined and edited (Lee et al. 2015; Lim et al. 2015a, 2016a).

2. As shown in Figure 3(b), the data are used to design a free-form building according the architect's intended concept. Based on the architect's intent, the order of step (1) and (2) may be switched.

3. As shown in Figure 3(c), the data on FCP composed of the free-form building's finish panel shape are extracted and sent to a computer (Lee 2015).

4. As shown in Figure 3(d), the transmitted data are input to a CNC machine and then, the rods move up and down to produce a three-dimensional free-forms shape (Lim et al. 2015b, 2016c). For reference, a rubber plate attached to the upper part of rods makes it possible to produce a smooth shape.

5. As shown in Figure 3(e), Composite PCM (Lee, Kim 2015; Lee et al. 2017) is poured into the upper part of rubber plate and cooled. A free-form mold at the solid state is produced.

6. As shown in Figure 3(f), concrete is poured into the PCM mold to produce FCP. Then, the form is removed. The PCM mold is changed to liquid and reused for producing other free-form molds (Lee 2015). The PCM mold produced using a CNC machine is permanently reusable as its phase changes from solid to liquid through cooling and melting. The most difficult part of FCP production is mold production. However, the study uses a machine to produce molds, which results in reduced construction time and high productivity as well as signifi- cant cost reduction owing to the increased number of reuses. For commercialization of this technology, the shape errors of FCPs need to be verified.

\subsection{Operation of CNC machine}

CNC machine is basically used to build a free-form shape and it moves the rods installed on the upper part up and down (Z-axis) as shown in Figure 2(a). As shown in Figure 2(b), NCRs are placed at $100 \mathrm{~mm}$-intervals and they can rise up to $100 \mathrm{~mm}$ toward the $\mathrm{Z}$-axis. In other words, the three-dimensional free-form shape of FCP is expressed by the values allocated to $\mathrm{X}, \mathrm{Y}$ and $\mathrm{Z}$-axes.

For instance, if the crossing of $\mathrm{X} 2$ and $\mathrm{Y} 1$ is defined as $\mathrm{P} 1$, that of $\mathrm{X} 3$ and $\mathrm{Y} 1$ as $\mathrm{P} 2$ and that of $\mathrm{X} 4$ and $\mathrm{Y} 1$ as $\mathrm{P} 3$ as shown in Figure 4, the height $\mathrm{H} 1, \mathrm{H} 2$ and $\mathrm{H} 3$ become the $\mathrm{Z}$ value. With the coordinate data, the CNC machine operates. In other words, the coordinate $\mathrm{Z}$ values controlled by the computer are the curved surface data of FCP. The free-form curved surface between coordinates is realized based on the rubber plate located at the upper part of rods as shown in Figure 3(d). When PCM such as wax is poured in and solidified as shown in Figure 3(e), the mold at the solid state is produced.

The precision of PCM mold produced based on the designed FCPs information in the process is influenced by the mechanical errors generated as the rods move up and down as well as the bending property of the rubber plate. Owing to these influence factors, there is a slight difference between the FCP design information and the final product. Herein, the experimental study analyzes the errors generated in the production process. The analyzed result will help to secure high-quality FCP production technology.

For reference, the operating time of $\mathrm{CNC}$ machine are relatively much shorter to compare with time required to solidify the PCM mold. Thus, the number of motors operating at one time is restricted to reduce the production cost and power consumption in the experiment stage. However, when producing commercial molds to produce FCPs that are $2 \times 2 \mathrm{~m}$ in size or larger, the number of motors may be increased for durability and quick operation. In addition, the number of rods may be increased and the intervals may be reduced to improve shape accuracy. The speci-

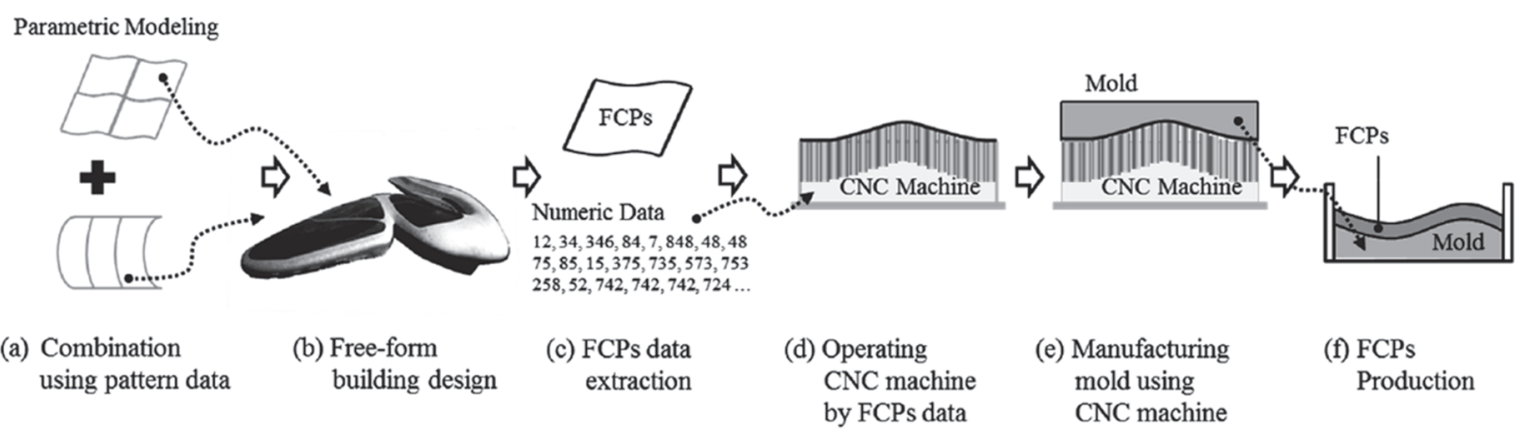

Figure 3. Production concept of FCPs using CNC machine (Lim et al. 2016a) 


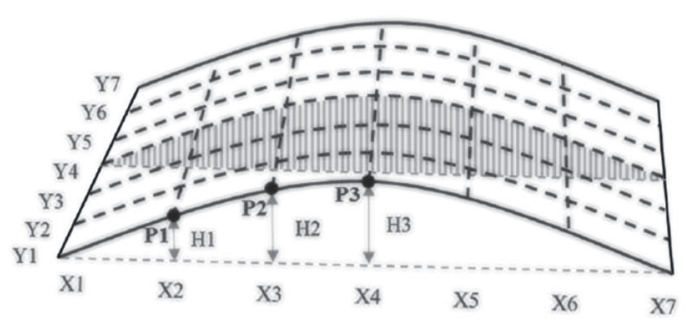

Figure 4. Setting coordinated free-form information

fications of the CNC machines, including these, should be addressed in further commercialization studies.

\section{FCP shape}

\subsection{FCP shape design}

To build a free-form shape, DDP, an existing free-form building was selected as a case project. Based on the case building, FCPs were designed for this experimental study. The brief information of the case building is shown in Table 1. The building and total floor area of DDP is $25,104 \mathrm{~m}^{2}$ and $83,024 \mathrm{~m}^{2}$, respectively. It is the largest free-form building in South Korea that is 4 stories high with 4 basement floors. The whole building is composed of three-dimensional curved surfaces. The building's cladding materials are perforated aluminum panels.

The general perspective view of DDP is as shown in Figure 5(a), and the building's cladding materials were examined (b) to choose a design sample (c). The enlarged design sample is as shown in Figure 5(d) and one out of four panels was chosen for design.

Although the free-form building seems dynamic with its large curvature, it is possible to find out that a free-form panel is in gentle curve as shown in the case project. The free-form building in the case project is curved as a whole
Table 1. Brief description of project

\begin{tabular}{|ll|}
\hline \multicolumn{1}{|c|}{ Description } & \multicolumn{1}{c|}{ Contents } \\
\hline Location & Seoul, South Korea \\
Construction time & $2008.09 .10-2013.11 .30$ (1,907 days) \\
Site area & $62,957 \mathrm{~m}^{2}$ \\
Building area & $25,104 \mathrm{~m}^{2}$ \\
Total floor area & $83,024 \mathrm{~m}^{2}$ \\
Volume & $43.98 \%$ \\
Building coverage & $39.25 \%$ \\
No. of floors & 4 stories above ground, 4 basement \\
Usage & stories \\
Structure & Cultural and convention center \\
Cladding materials & Steel and reinforced concrete \\
\hline
\end{tabular}

at an angle of $340^{\circ}$ as shown in Figure 5(c), and has a generally large curvature. However, one subdivided FCP is single-curved with a gentle bend at a radius of $987 \mathrm{~mm}$ and $9^{\circ}$ angle as shown in Figure 5(d).

FCP was designed as shown in Figure 6 based on the curvature and size of the cladding in Figure 5(d). With Fusion 360 Program, FCP that is $600 \mathrm{~mm} \times 600 \mathrm{~mm}$ in size was $3 \mathrm{D}$-designed (a). The FCP shape was designed in size that is same as that of the CNC machine's NCRs array, and the design shape was split at $100 \mathrm{~mm}$-intervals $(7 \times 7)$ as corresponding to the $\mathrm{X}$ and $\mathrm{Y}$ coordinates. The partitioned shape coordinates were named as X1-X7 and Y1-Y7 (d), and the height difference of min-max was designed as $46.7 \mathrm{~mm}$.

For CNC machine operation, the Z-value for each coordinate of free-form shape partitioned by NCR-intervals was measured as shown in Table 2. The designed shape had the convex curvature with overall symmetry. Thus, the same values were measured, $0 \mathrm{~mm}$ for the $\mathrm{X} 1$ and $\mathrm{X} 7$

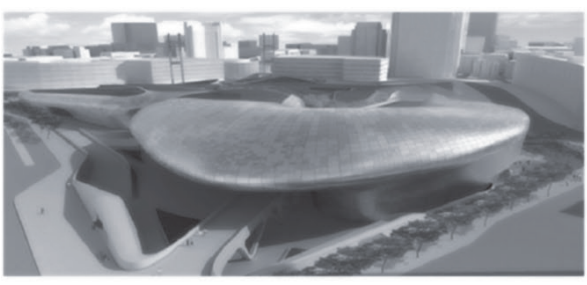

(a) General perspective view of DDP (Hwang 2014)

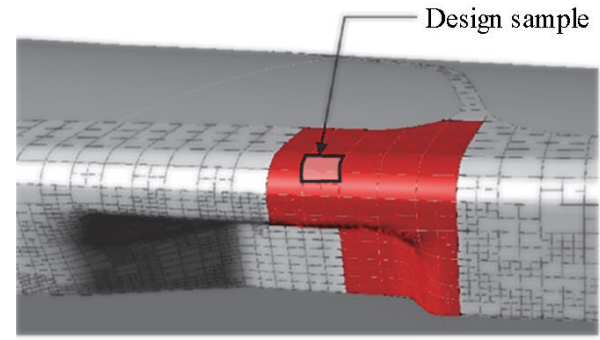

(c) Selection of sample for shape design

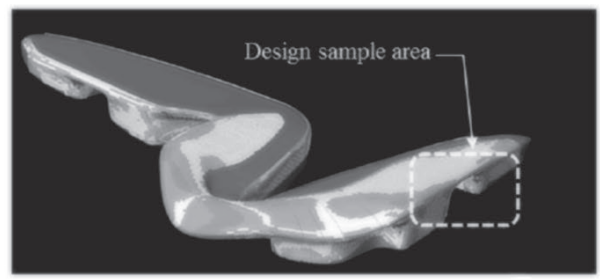

(b) Review for free-form shape of cladding (Hwang 2008)

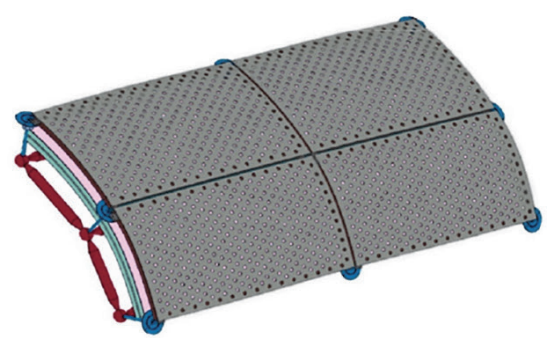

(d) Design sample

Figure 5. Design sample for experiment of CNC machine 


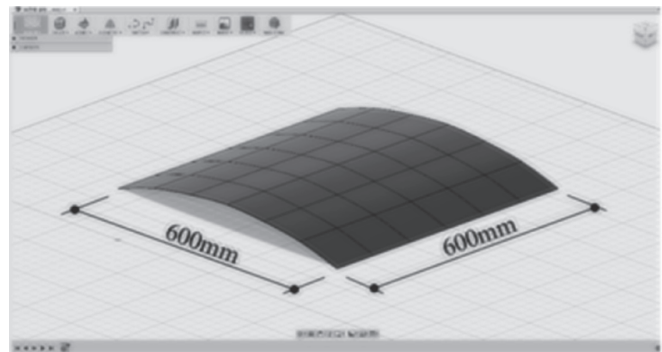

(a) General perspective view

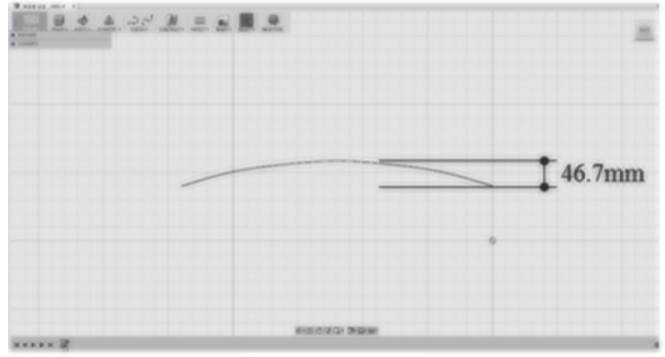

(c) Front view

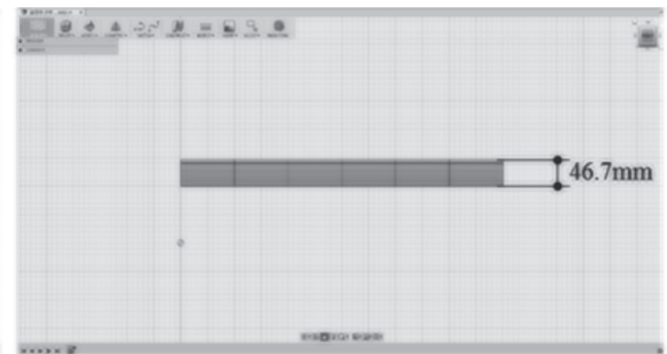

(b) Side view

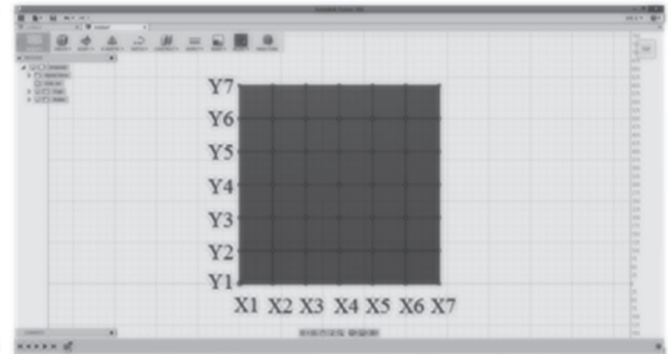

(d) Plane view (Lim et al. 2016b)

Figure 6. FCP shape design

values, $26.7 \mathrm{~mm}$ for the $\mathrm{X} 2$ and $\mathrm{X} 6$ values, $40 \mathrm{~mm}$ for the $\mathrm{X} 3$ and X5 values and $46.7 \mathrm{~mm}$ for the X4 value. Here, the minimum value $0 \mathrm{~mm}$ was set as the reference value for easier CNC operation and experiment on error measurement.

\subsection{FCP shape error experiment}

In order to verify the quality of FCP using CNC machine, an experimental plan on shape error was established as shown in Figure 7. The CNC machine was operated to check the difference between the value that the shape plate implemented and the designed coordinate value. The difference indicates the vertical error between the implemented shape and the design.

For the experiment, first, the CNC machine is operated based on the FCP shape (a). Second, a rubber is attached to the CNC machine (b). After the attachment, a square frame is fixed on top of the $\mathrm{CNC}$ machine to measure the distance between the rubber and the top of square frame (c). With
Table 2. Coordinate values of FCP shape design (unit: $\mathrm{mm}$ )

\begin{tabular}{|cccccccc|}
\hline Classification & $\mathrm{X} 1$ & $\mathrm{X} 2$ & $\mathrm{X} 3$ & $\mathrm{X} 4$ & $\mathrm{X} 5$ & $\mathrm{X} 6$ & $\mathrm{X} 7$ \\
\hline Y1 & 0 & 26.7 & 40 & 46.7 & 40 & 26.7 & 0 \\
Y2 & 0 & 26.7 & 40 & 46.7 & 40 & 26.7 & 0 \\
Y3 & 0 & 26.7 & 40 & 46.7 & 40 & 26.7 & 0 \\
Y4 & 0 & 26.7 & 40 & 46.7 & 40 & 26.7 & 0 \\
Y5 & 0 & 26.7 & 40 & 46.7 & 40 & 26.7 & 0 \\
Y6 & 0 & 26.7 & 40 & 46.7 & 40 & 26.7 & 0 \\
Y7 & 0 & 26.7 & 40 & 46.7 & 40 & 26.7 & 0 \\
\hline
\end{tabular}

the difference between the measured distance and the height of square frame, its shape error is checked.

The rubber used as the shape plate is made from rubber or silicon materials, making it naturally flexible. It not only allows the free-form shapes to be smooth and continuous as the rods move up and down, but also makes it easier to measure shape errors. In a study by Janssen (2011), a heavy

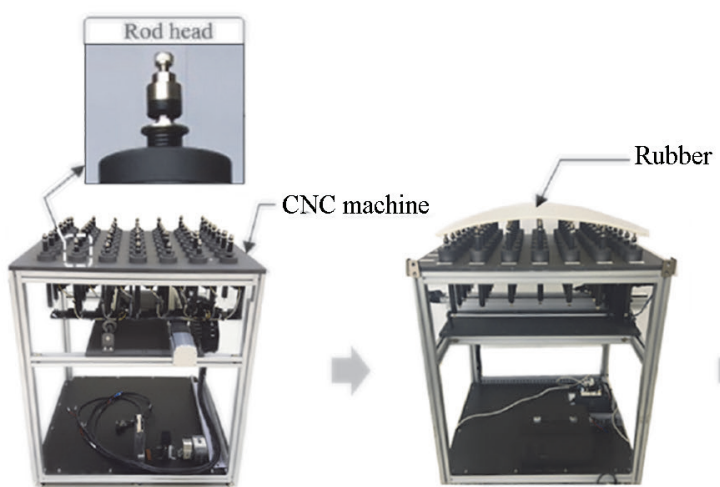

(a) Operating NCRs of CNC machine (b) Fixing rubber to $\mathrm{CNC}$ machine
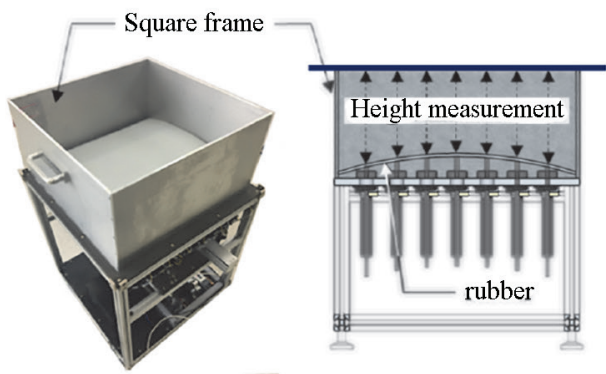

(c) Height measurement using square frame

Figure 7. FCP shape error experiment 
duty rubber is needed which can withstand deformation due to concrete pressure, because it is directly cast on the rubber plate. However, in this study, a light duty rubber plate that supports only the weight of the PCM mold is required. Since the concrete specific gravity is 2.4 and the specific gravity of PCM (paraffin) is 0.9 , it is confirmed that deformation by the material placed on the rubber plate of this study is relatively small. If the rod head is fixed because of the height difference with the neighboring rod, the rubber may be implemented as a steep plane instead of a smooth, gentle curve. To solve this problem, Huyghe and Schoofs (2009), Savvides (2012) suggested that it should be designed for free rotation. In reflection of this, the NCR's head was designed as shown in Figure 7(a).

To verify the FCP shape based on design, its measurement location was set. Since Y1-Y7 rows have the same measured values, the representative location at $\mathrm{Y} 1$ was expressed as shown in Figure 8. To examine changes in shape errors depending on the NCR spacing, it was measured at regular intervals. $100 \mathrm{~mm}$-intervals between NCRs were equally divided into 10 sections and it was measured 61 times in total at $\mathrm{Y} 1$ row at $10 \mathrm{~mm}$-intervals.

\section{Analysis of FCP quality}

It is difficult to determine the FCP shape errors visually. However, when the accurately measured data are expressed in graphs or charts as shown in Figure 9, the errors may be checked. Each line is the coordinate value of designed model and the mean value per location of data,

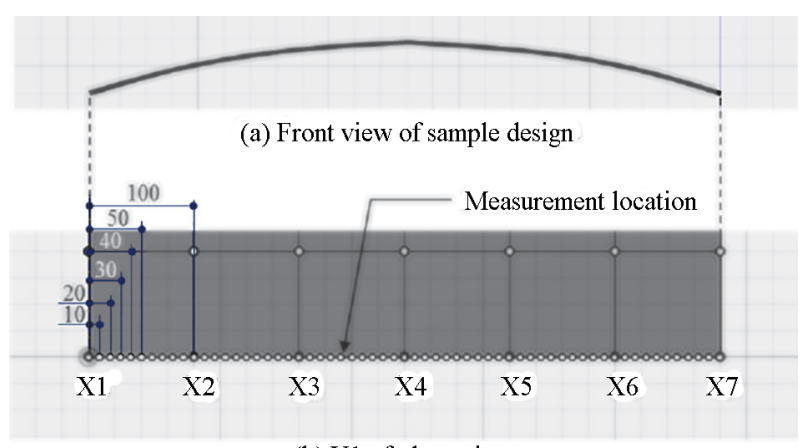

(b) Y1 of plane view

Figure 8. Measurement location of FCP sample design

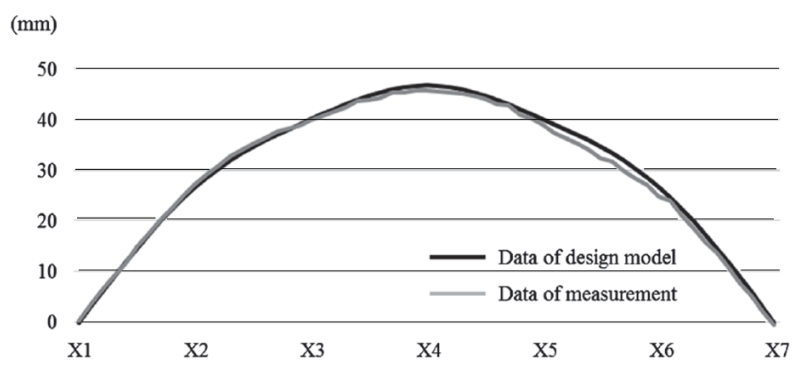

Figure 9. Error measurement result

and its difference is the FCP shape error. To check the errors in detail, the ratio of shape design was not applied as it is, but the height of $\mathrm{Z}$-axis was increased 5 times on the graph.

The descriptive statistics on experiment result of $\mathrm{CNC}$ machine regarding the FCP shape design is shown in Table 3. For overall analysis and easier separation, each experiment is titled as Test 1 6 according to the measurement point and NCR distance. It was measured 427 times in total. Its average is $0.36 \mathrm{~mm}$, the average of standard deviation is $1.05 \mathrm{~mm}$, and the maximum value is $4.6 \mathrm{~mm}$.

When it was $10 \mathrm{~mm}$ away from NCR, there was $0.18 \mathrm{~mm}$ difference in average, and when it was $20 \mathrm{~mm}$ away from NCR, there was $0.26 \mathrm{~mm}$ difference in average. When it was $30 \mathrm{~mm}$ away from NCR, there was $0.35 \mathrm{~mm}$ difference in average, and when it was $40 \mathrm{~mm}$ away from NCR, there was $0.61 \mathrm{~mm}$ difference in average. When it was $50 \mathrm{~mm}$ away from NCR, there was $0.63 \mathrm{~mm}$ difference in average. The maximum error was measured when it was $50 \mathrm{~mm}$ away from NCR, which is equivalent to $4.6 \mathrm{~mm}$. In other words, it was found that the error increases as it gets farther away from the NCR according to the data analyses.

Based on the mean of shape errors measured at the point $10 \mathrm{~mm}, 20 \mathrm{~mm}, 30 \mathrm{~mm}, 40 \mathrm{~mm}$ and $50 \mathrm{~mm}$ away from NCR, ANOVA analysis was conducted. As shown in the equation below, the null hypothesis $\left(\mathrm{H}_{0}\right)$ is the means of 5 groups are same' and the alternative hypothesis $\left(\mathrm{H}_{1}\right)$ is 'the means of 5 groups are different'. It was verified at the confidence level of $95 \%$ :

$\mathrm{H}_{0}$ : The means of 5 groups are same;

$\mathrm{H}_{1}$ : The means of 5 groups are different.

Table 3. Descriptive statistics by distance from NCR (unit: $\mathrm{mm}$ )

\begin{tabular}{|c|c|c|c|c|c|c|c|c|}
\hline \multirow{2}{*}{ Test } & \multirow{2}{*}{$\begin{array}{l}\text { Distance } \\
\text { from NCR }\end{array}$} & \multirow{2}{*}{$\mathrm{N}$} & \multirow{2}{*}{ Mean } & \multirow{2}{*}{$\begin{array}{c}\text { Std. } \\
\text { Deviation }\end{array}$} & \multirow{2}{*}{$\begin{array}{l}\text { Std. } \\
\text { Error }\end{array}$} & \multicolumn{2}{|c|}{ 95\% Confidence Interval for Mean } & \multirow{2}{*}{ Max. } \\
\hline & & & & & & Lower bound & Upper bound & \\
\hline 1 & 0 & 49 & 0.00 & 0.00 & 0.00 & 0.00 & 0.00 & 0.0 \\
\hline 2 & 10 & 84 & 0.18 & 0.52 & 0.06 & 0.06 & 0.29 & 1.2 \\
\hline 3 & 20 & 84 & 0.26 & 0.71 & 0.08 & 0.10 & 0.41 & 1.6 \\
\hline 4 & 30 & 84 & 0.35 & 0.91 & 0.10 & 0.15 & 0.55 & 1.9 \\
\hline 5 & 40 & 84 & 0.61 & 1.22 & 0.13 & 0.35 & 0.88 & 2.9 \\
\hline 6 & 50 & 42 & 0.63 & 1.42 & 0.22 & 0.19 & 1.08 & 4.6 \\
\hline & Total & 427 & 0.36 & 1.03 & 0.05 & 0.26 & 0.46 & 4.6 \\
\hline
\end{tabular}


Table 4. ANOVA (Error per distance from NCR)

\begin{tabular}{|lccccc|}
\hline \multicolumn{1}{|c}{ Classification } & Sum of squares & Degree of freedom & Mean square & F & Significance probability \\
\hline Between groups & 18.42 & 4 & 3.68 & 4.57 & 0.00 \\
Within group & 339.30 & 421 & 0.81 & - & - \\
Total & 357.72 & 426 & - & - & - \\
\hline
\end{tabular}

ANOVA analysis was based on 427 data in total, and the result is shown in Table 4. It was analyzed that F-value is F-value 4.57 and P-value is 0.00 . Thus, the null hypothesis $\left(\mathrm{H}_{0}\right)$ can be rejected. It was found that as it gets farther away from NCR when compared to the average of five groups, the error significantly increases.

Based on the experimental data of shape errors, a regression model between variables was drawn. The regression model is the basis for estimating the shape error that may be generated according to the distance from NCR. The summary of this regression model on shape errors is shown in Table 5 . It was analyzed that R-square value is 0.05 and the standard deviation of observed value is 0.89 . The regression line that represents the relationship of shape errors was estimated, and it is as shown in Eqn (3). It was confirmed that when it gets $1 \mathrm{~mm}$ away from NCR, the shape error increases by $0.013 \mathrm{~mm}$. Additionally, variance was analyzed to test the significance of regression model, and its result is shown in Table 6. It was analyzed that Fvalue is 21.829 and $\mathrm{P}$-value is 0.00 . Thus, the regression model is statistically significant at the significance level of 0.05 .

$$
y=0.010+0.013 x
$$

For analysis of shape errors, the wall thickness should be within 3\% in accordance with Article 20 of the Building Act Enforcement Ordinance on the allowable error standard. The FCP thickness is set as $150 \mathrm{~mm}$ with an error range of $4.5 \mathrm{~mm}$. As shown in the equations below, the null hypothesis $\left(\mathrm{H}_{0}\right)$ was set as $|\bar{x}| \geq 4.5$ and the alternative hypothesis $\left(\mathrm{H}_{1}\right)$ was set as $|\bar{x}|<4.5$. The experimental values were calculated using Z-distribution. It was confirmed that the test statistic is -83.23 which is smaller than the threshold of significance value (1.645), making it possible to reject the null hypothesis. Thus, it can be said that the shape error is smaller than $4.5 \mathrm{~mm}$. In other words, it was verified that CNC machine is suitable for FCP production:

$$
\begin{aligned}
& \mathrm{H}_{0}:|\bar{x}| \geq 4.5 ; \\
& \mathrm{H}_{1}:|\bar{x}|<4.5 .
\end{aligned}
$$

Before conducting an experiment to verify whether FCP quality is assured using a CNC machine, the following assumptions were made. It may be difficult to implement an accurate FCP shape owing to: 1) accumulated mechanical errors; and 2) errors caused by material properties.

As a result, the parts near NCR are capable of implementing shapes that are similar to the FCP shape since the CNC machine is composed of NCRs, and uses data transmitted for implementation. However, when it gets farther away from the NCR, errors are generated. The reason is that first, deformation occurs between NCRs due to the elastomer property of rubber, and second, rubber is thinner than the original thickness due to the tension between the NCRs during the process of embodying the shape of the sample design. Among the assumptions mentioned above, it may be largely due to the error caused by material properties.

Additionally, the materials of shape plates affect the FCP quality. As shown in Figure 9, the largest errors were generated from $\mathrm{X} 4$ to $\mathrm{X} 6$ sections during the experiments on shape errors. As examining its reasons, it was confirmed that the rubber surface was not smooth and its thickness was not constant unlike the other sections. Therefore, further studies on free-form building technologies to implement FCP shapes without using NCRs and rubber are needed.

Table 5. Regression model summary

\begin{tabular}{|ccccc|}
\hline Model & $\mathrm{R}$ & R-square & Adjusted R-square & Standard error of estimated value \\
\hline 1 & $0.221 \mathrm{a}$ & 0.049 & 0.047 & 0.89 \\
\hline
\end{tabular}

Table 6. ANOVA (Regression model)

\begin{tabular}{|llccccc|}
\hline & Model & Sum of squares & Degree of freedom & Mean square & F & Significance probability \\
\hline \multirow{4}{*}{1} & Regression & 17.476 & 1 & 17.476 & 21.829 & $0.000 \mathrm{~b}$ \\
\cline { 2 - 4 } & Residual & 340.242 & 425 & 0.801 & - & - \\
& Total & 357.718 & 426 & - & - & - \\
\hline
\end{tabular}




\section{Conclusions}

The conventional three-dimension curved surface displaying machines are expensive with complicated design, and it was difficult to be applied to construction sites. To solve this problem, an inexpensive CNC machine that can implement FCP shapes was developed. This study conducted experimental study on shape errors using a CNC machine to verify FCPs production quality. The total number of shape errors measured in the study was 427 times, and such data were used to compare with the designed FCP coordinate values. The conclusion drawn from the study is as follows.

First, before conducting an experiment to verify FCP quality using a $\mathrm{CNC}$ machine, the following assumptions were made. It may be difficult to implement an accurate FCP shape owing to: 1) accumulated mechanical errors; and 2) error caused by materials properties. As a result, it was confirmed that the shape error increases by $0.013 \mathrm{~mm}$ when it is $1 \mathrm{~mm}$ away from the NCR. The reason is that the rubber is an elastic body, so tension occurs between the NCRs, which causes deformation and the rubber is thinner than the original thickness. Among the assumptions mentioned above, it may be largely due to the error caused by material properties.

Second, when the FCP thickness is set as $150 \mathrm{~mm}$, the allowable error should be within $4.5 \mathrm{~mm}(3 \%)$ in accordance with the Building Act Enforcement Ordinance. It was found from the calculated experimental values that the FCP shape error is smaller than $4.5 \mathrm{~mm}$. It was verified that the $\mathrm{CNC}$ machine is suitable for FCP production.

Third, according to the experiment on shape errors, there was a greater error in a specific section. This was because the rubber surface was not smooth and its thickness was inconsistent unlike other sections. In other words, it was confirmed that the materials of shape plates affect the FCP quality when the CNC machine is adopted.

The study verified that the FCP production technology using the CNC machine is capable of implementing uniform quality FCPs without depending on the skills and workmanship of the labor. However, it was confirmed that the NCR periphery can implement the shape most similar to the FCP shape with compared to far from NCR. And, it was confirmed the FCP quality depends on the materials of shape plates when the CNC machine is applied. Thus, free-form building technologies that can implement FCP shapes without using NCRs and rubber are needed. Additionally, further studies on 3D carving techniques that can implement accurate FCP designs need to be conducted. When manufacturing FCPs using a CNC machine, it is difficult to process the edge treatment, but it is very important to keep the contours between the FCPs closely and require a more precise mathematical solution. Therefore, further research is needed to solve this issue.

\section{Acknowledgements}

This work was supported by the National Research Foundation of Korea (NRF) grant funded by the Korea government (MOE) (No. 2017R1D1A1B04033761).

\section{References}

4TU (The four universities of technology) [online], 2017 [cited 20 December 2017]. Available from Internet:

https://www.4tu.nl/bouw/en/LHP2014/kine-mould/

Adapa [online], 2017 [cited 20 December 2017]. Available from Internet: http://adapa.dk/

Bae, K. J.; Lee, S. H.; Jun, H. J. 2009. A study on digital design process of the materialization of free form design architecture, in 2009 Autumn Annual Conference of the Architectural Institute of Korea 29(1): 221-224.

CRAFT (Center for Rapid Automated Fabrication Technologies) [online], 2014 [cited 15 July 2014]. Available from Internet: http://www.craft-usc.com/

Huyghe, K.; Schoofs, A. 2009. Precast double curved concrete panels: Master's thesis. Delft University of Technology.

IMCRC (Innovative Manufacturing and Construction Research Center) [online], 2014 [cited 15 July 2014]. Available from Internet: http://www.lboro.ac.uk/eng/research/imcrc/

Ito, T. 2006. Meiso no mori crematorium gifu. Japan Toyo Ito \& Associates Meiso no Mori Crematorium Gifu, Japan Toyo Ito \& Associates nd.

Janssen, B. 2011. Double curved precast load bearing concrete elements: Master's thesis. Delft University of Technology.

Kim, K. 2014. Development of production and management technology of free-form concrete segment: Master's thesis. Kyung Hee University of Architectural Engineering.

Kim, K.; Son, K.; Kim, E. D.; Kim, S. 2015. Current trends and future directions of free-form building technology, Architectural Science Review 58(3): 230-243.

https://doi.org/10.1080/00038628.2014.927751

Kim, S. W. 2009. Classification and optimization of irregularshaped building panels by fabrication methods: Focused on Dongdaemun Design Plaza and Park: Master's thesis. Yonsei University of Architectural Engineering.

Latorre, J. I. P. 2010. Construction method to build ice shells with pneumatic formwork: Master's thesis. Vienna University of Technology Faculty of Civil Engineering.

Lee, D. 2015. A study of construction and management technology of free-form buildings: Doctor's thesis. Kyung Hee University of Architectural Engineering.

Lee, D.; Kim, S. 2015. Development of PCM-enabled a typical concrete segment production process, Journal of the Regional Association of Architectural Institute of Korea 17(1): 219-224.

Lee, D.; Lee, S. G.; Kim, S. 2017. Composite phase-change material mold for cost-effective production of free-form concrete panels, Journal of Construction Engineering and Management 143(6), 04017012.

https://doi.org/10.1061/(ASCE)CO.1943-7862.0001300

Lee, D.; Lim, J.; Habimana, G.; Lee, T. O.; Kim, S. 2015. Automatic panelizing algorithms of free-form buildings, in $6^{\text {th }}$ International Conference on Construction Engineering and Project Management (ICCEPM 2015), 2015, Korea Institute of Construction Engineering and Management, Busan, Korea, 425-428.

Lee, J. S. 2008. BIM in terms of architectural design, construction technology, Ssangyong Institute of Construction Technology 48: 22-27. 
Lim, J.; Habimana, G.; Han, K.; Kim, J. T.; Kim, S. 2015a. Panelizing algorithms for free-form concrete panels considering esthetic surfaces, International Journal of Technology and Engineering Studies 1(3): 81-86. https://doi.org/10.20469/ijtes.40003-3

Lim, J.; Lee, D.; Na, Y.; Lim, C.; Kim, S. 2015b. A productioninstallation simulation model of free-form concrete panels, in $6^{\text {th }}$ International Conference on Construction Engineering and Project Management (ICCEPM 2015), 2015, Korea Institute of Construction Engineering and Management, Busan, Korea, 401-404.

Lim, J.; Son, S.; Cho, W.; Kim, S. 2016a. Pattern data for automatic design of free form panels, in The International Congress of Engineering and Information (ICEAI), Osaka, Japan, 1149-1156.

Lim, J.; Son, S.; Na, Y.; Kim, S. 2016b. A basic study of experiment using $\mathrm{CNC}$ machine for quality of free-form concrete panels, Proceedings of the 2016 Autumn Annual Conference of the Architectural Institute of Korea 36(2): 953-954.

Lim, J.; Yue, L.; Na, Y.; Kim, S. 2016c. Four cases of production-installation simulation for free-form concrete panels, Journal of Advances in Technology and Engineering Research 1(2): 22-27. https://doi.org/10.20474/-jater2.1.5

Lindsey, B.; Gehry, F. O. 2001. Digital Gehry: Material resistance digital construction. Springer Science \& Business Media, 19-22.

Mandl, P.; Winter, P.; Schmid, V. 2008. Free-forms in composite constructions, in The New House of Music and Music Theatre "Mumuth" In Graz. Eurosteel 2008, Austria.

Oesterle, S.; Vansteenkiste, A.; Mirjan, A. 2012. Zero waste free-form formwork, in Second International Conference on Flexible Formwork, ICFF. CICM and University of Bath, Dept. of Architecture and Civil Engineering.

Payne, J. 2003. The Sydney Opera House, inside and out.

Plaza, B. 2006. The return on investment of the Guggenheim Museum Bilbao, International Journal of Urban and Regional Research 30(2): 452-467. https://doi.org/10.1111/j.1468-2427.2006.00672.x

Ryu, H. G.; Kim, S. J. 2012. Case study of concrete surface design and construction method for freeform building based on BIM: focused on Tri-Bowl, Korea, Journal of the Korea Institute of Building Construction 12(3): 347-357. https://doi.org/10.5345/JKIBC.2012.12.3.347

Savvides, A. 2012. 3.F.S.T.(Free form formwork system technology for concrete structures): Master's thesis. Budapest University of Technology and Economics.

Schipper, H. R.; Janssen, B. 2011. Manufacturing double-curved elements in precast concrete using a flexible mould: First experimental results, in Proceedings FIB Symposium, Concrete Engineering for Excellence and Efficiency, 8-10 June 2011, Prague, Czech Republic.

Schipper, H.; Eigenraam, P. 2016. Mapping double-curved surfaces for production as precast concrete shell elements, HERON 61: 211-234.

Verhaegh, R. W. A. 2010. Free forms in concrete fabric: Master's thesis. Eindhoven University of Technology. 